\title{
Further biomimetic challenges from the bombardier beetle: the intricate chemical production system
}

\author{
A. C. McIntosh \& A. Prongidis \\ Energy and Resources Research Institute, University of Leeds, UK
}

\begin{abstract}
Since the important work by Eisner showing the nature of the bombardier beetle pulse ejection system, a considerable number of biomimetic advantages have been gained by mimicking the unique spray system based on the unique coordinated inlet and outlet valve system that the beetle has.

This paper discusses the equally remarkable production by the bombardier beetle of hydroquinone and hydrogen peroxide, followed by the catalytic combustion of these reactants and subsequent heating of the water diluent and the emergence of the hot caustic spray through a nozzle that can be turned in any direction.

This paper considers the possible chemical mechanisms for the production of hydrogen peroxide within the narrow tube. The current production of peroxide is usually by a batch chemical autoxidation process involving a number of stages of which the two main ones are firstly a hydrogenation reaction of anthroquinone over Ni or Pd catalysts producing anthroquinol, then secondly followed by an oxidiser reaction where the anthroquinol is turned back to anthroquinone and hydrogen peroxide. This method involves considerable energy expended in heating and cooling at each stage and condensing out the peroxide from the water $-\mathrm{H}_{2} \mathrm{O}_{2}$ mixture at the end of the process. The bombardier beetle is able to produce the peroxide at room temperature with little energy loss in the system. Although there are some similarities to the current industrial method, the benefits of mimicking the beetle system are obviously very beneficial in terms of the greatly increased efficiency of peroxide production.
\end{abstract}

Keywords: biomimetics, chemistry, bleach production, bombardier beetle, hydrogen peroxide, hydroquinone. 


\section{Introduction}

The unique defence mechanism of the bombardier beetle squirts a hot spray of water/steam at $100^{\circ} \mathrm{C}$, mixed with quinones, on any predators such as ants, frogs and birds. Known for many years by entymologists, this stunning defence mechanism has been brought with fresh vigour to the attention of the scientific community, particularly through the pioneering work of Aneshansley et al. [1] who found that the spray is formed by a pair of glands that open at the tip of the beetle's abdomen and the photographic evidence [2] in particular demonstrated that the beetle chamber undergoes a series of fast cyclic reactions that heat the water mixture so rapidly that the spray which emanates from the exhaust of this system is not a continuous stream but a series of micro and audible explosions. By rotating the tip of this exhaust located near the abdomen tip, the beetle can aim its weapon in any direction with pin point accuracy in any direction, even ejecting it forward from over the back.

Over a number of years a biomimetic study begun by the University of Leeds has focused on the spray system of the bombardier beetle and in particular the physics of the remarkable valve system attached to the twin combustion chambers, which are of the order of $1 \mathrm{~mm}$ long. The results of this study [3-8] have exposed an intriguing use that the beetle makes of flash evaporation and boiling where the solution of water mixed with quinones is held under pressure above boiling and then released suddenly by a pressure relief valve. When a rig was built to mimic this at Leeds, it was found that the characteristics of the spray were of great industrial interest and have a wide number of practical applications, including pharmaceutical inhalers and fuel injectors in engines and fire extinguishers [9]. The ejection can be a wide fine spray or can be with a very powerful throw capability, both of which in different applications are of great interest.

The biomimetics of the study of the beetle should not end though with simply the physics of this rather extraordinary design in this small part of the bombardier beetle's anatomy. There are other features that are equally astonishing and have some profound implications for those in search of innovative engineering. There are material properties of the chamber itself that still need studying in much greater detail to ascertain whether there are peculiar properties of the chamber walls (collagen based) that give great insulation, such that the very hot fluid (essentially a water and steam mixture) does not scald the rest of the beetle's anatomy. There are also issues to do with the tank-like turret at the back of the abdomen of the beetle that can swivel in any direction in all three dimensions. This is of great mechanical interest and could give clues for inspiring novel joint engineering. The sensing system also needs investigating how the beetle senses the precise location of its attacker is not yet fully understood (the beetle usually is not facing its attacker - often a bird, a spider, frog or ant) and it usually wins. It is thought that sensory smell organs are probably involved. The response time is exceedingly fast, and it is not yet known whether both of the twin combustion chambers exhaust in tandem or one first, 
then followed by the other. The catalysts catalase and some peroxidises are reckoned to be attached in crystalline form on the inside hairs of the chamber this is another area that needs careful investigation, as there may be a most useful catalytic application from such features.

Connected with the overall chemistry, however, perhaps one of the most intriguing matters that awaits a full understanding is the question of the chemical reactant supply before even entering the chamber. Of particular interest is the chemistry of the hydrogen peroxide manufacture. We do not yet know the answer to all the issues raised concerning how the chemistry works, but wish to begin the process of investigation so that pertinent questions are addressed, since there are a raft of possible uses for a cheap way of producing Hydrogen Peroxide.

First we present a summary of the chemistry used in the chamber itself. Schildknecht and Holoubek [10] discovered that each of the twin systems consists of a gland with two compartments; a reservoir and a reaction chamber that are connected through a valve. In Fig. 1, the details of the two compartments are illustrated for one of the glands. The reservoir contains an aqueous solution of hydroquinones and hydrogen peroxide, while the reaction chamber is filled with a mixture of catalase and peroxidases dissolved in water. Muscles on the reservoir squeeze it and push the quinone/peroxide solution into the reaction chamber which, with the waiting catalysts, triggers an extremely fast reaction in the reaction chamber. The catalase decomposes the hydrogen peroxide and the peroxidases oxidise the hydroquinone to benzoquinone. Current thinking, as mentioned earlier, suggests that these enzymes (catalase and peroxidases) are injected from tiny glands in the reaction chamber wall. Aneshansley et al. [11] describe the reaction mechanism as:

$$
\mathrm{C}_{6} \mathrm{H}_{6} \mathrm{O}_{2}(a q)+\mathrm{H}_{2} \mathrm{O}_{2}(a q) \longrightarrow \mathrm{C}_{6} \mathrm{H}_{4} \mathrm{O}_{2}(a q)+2 \mathrm{H}_{2} \mathrm{O}(l)
$$

with three main decomposition steps:

$$
\begin{gathered}
\mathrm{C}_{6} \mathrm{H}_{6} \mathrm{O}_{2}(a q) \longrightarrow \mathrm{C}_{6} \mathrm{H}_{4} \mathrm{O}_{2}(a q)+\mathrm{H}_{2}(g) \\
\mathrm{H}_{2} \mathrm{O}_{2}(a q) \longrightarrow \mathrm{H}_{2} \mathrm{O}(\mathrm{l})+\frac{1}{2} \mathrm{O}_{2}(g) \\
\mathrm{H}_{2}(\mathrm{~g})+\frac{1}{2} \mathrm{O}_{2}(g) \longrightarrow \mathrm{H}_{2} \mathrm{O}(\mathrm{l})
\end{gathered}
$$

and the overall heat of reaction is calculated by summing the three individual heats of reactions. The overall heat release is $-202.8 \mathrm{~J} / \mathrm{mol}$. Noting the concentrations of the reactants from [10], the heat content of the reservoir solution is found to be $0.794 \mathrm{~J}$ per milligram of the solution. Calorimetric measurements of the ejected sprays from beetles confirmed the accuracy of this estimate. The heats of reaction for each step are listed by Schildknecht and Holoubek [10]. At $25^{\circ} \mathrm{C}$, they are $+177.2 \mathrm{~kJ} \mathrm{~mol}^{-1},-94.5 \mathrm{~kJ} \mathrm{~mol}^{-1}$ and $-285.5 \mathrm{~kJ}$ $\mathrm{mol}^{-1}$ respectively. The spray temperature at the exit point was measured to be 


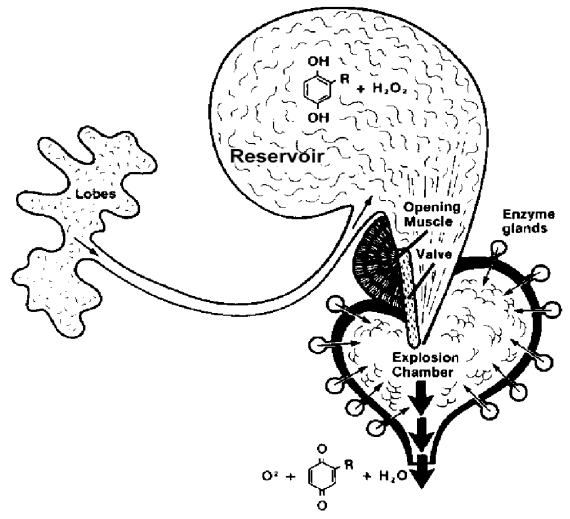

Figure 1: Schematic of the bombardier beetle discharge apparatus.

$100^{\circ} \mathrm{C}$. The above mentioned amount of heat is sufficient to bring all the spray from ambient temperature to boiling point and vaporize approximately one-fifth of it.

\section{The extremely thin tube reactor used by the bombardier beetle to produce hydrogen peroxide}

The way the hydrogen peroxide is produced is within an extremely narrow tube. However, the intriguing facts concerning the chemical system of the beetle are that not only the Hydrogen Peroxide, but also the Hydroquinone come from the same thin tube that the scanning electron microscope photographs reveal to be of the order of 1 micron $\left(10^{-6} \mathrm{~m}\right)$ in diameter, and to be of the order of a remarkable 50,000 micron (i.e. around $5 \mathrm{~cm}$ ) in length (longer than the beetle itself, which generally is not more than $2-3 \mathrm{~cm}$ ). This extremely thin yet robust system is closed off from the digestive parts of the beetle and wrapped round in a spiral strand above the inlet valve to the combustion chamber, which is shaped like a boxing glove (see Fig. 2). That both reactants are produced together is somewhat astonishing, since $\mathrm{H}_{2} \mathrm{O}_{2}$ is so reactive.

Within the tube there appears to be the ability to synthesise both chemicals together before entry into the combustion chamber. Then in this combustion chamber the two chemicals, with a water diluent, are combined in the presence of the catalysts catalase and peroxidase, to produce benzoquinone and steam according to equations (2)-(4).

It is not known what the input reactants are in to the end of the tiny tubes. No dissections of the tubes themselves have been made or chemical analyses of them, so what follows is a working possible thesis of the chemical route, and we are greatly indebted to Dr. John Cooper of the Explosives Group Technical Centre in Stevenston, Ayrshire [12] who has communicated a possible scheme. 


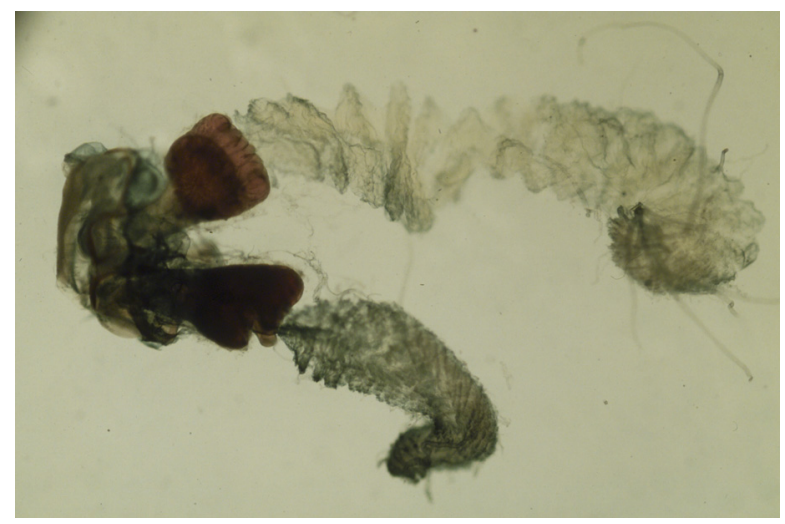

Figure 2: Photograph of extremely thin tubing within which the reactants are produced, including $\mathrm{H}_{2} \mathrm{O}_{2}$. Photograph courtesy of T. Eisner, Cornell University.

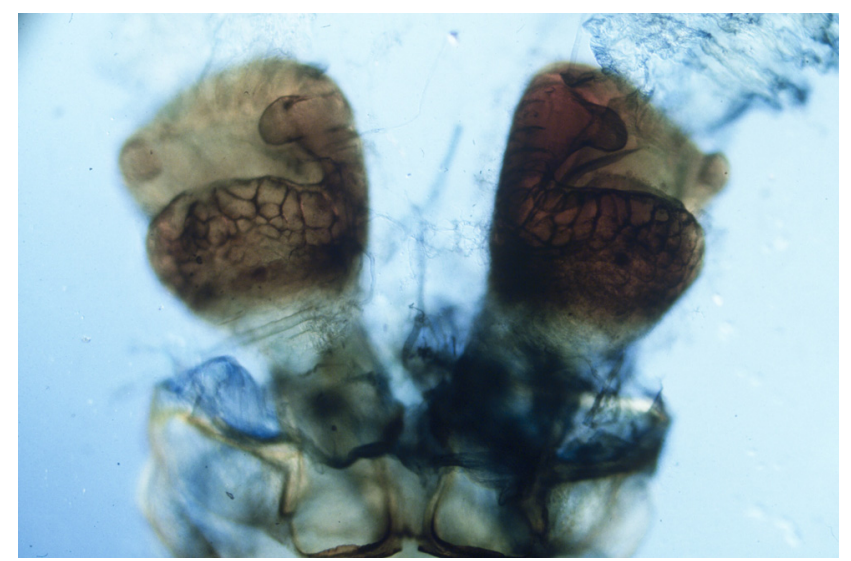

Figure 3: 'Boxing glove' like arrangement of the twin combustion chambers and nozzles of the bombardier beetle (Stenaptinus insignis) from a dissection by T. Eisner, Cornell University. Photograph courtesy of T. Eisner, Cornell University.

\subsection{Possible chemical route}

It is suggested that the beetle makes within itself a starting compound made of a quinol. This is prevalent in beetles, as it is quinol compounds (e.g. anthraquinol $\mathrm{C}_{14} \mathrm{H}_{10} \mathrm{O}_{2}$ ) and phenols (with only one hydroxyl attached to the carbon ring) that produce the variety of smells which play such an important part in insect existence. In this case we know that hydroquinol is involved, and it is suggested that the oxidation of the hydroquinol $\mathrm{C}_{6} \mathrm{H}_{6} \mathrm{O}_{2}$ is taking place in the very thin tube. Thus 


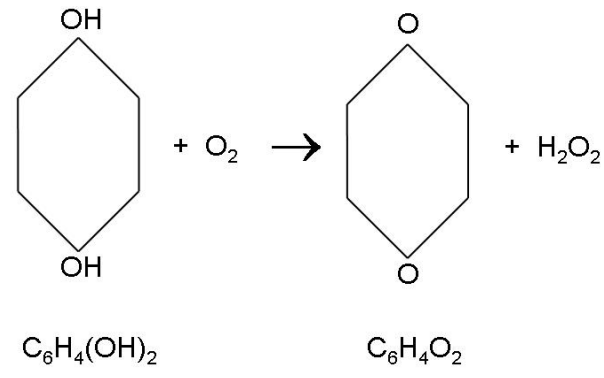

Hydroquinol

Benzoquinone

It is likely that the thin tube is essential for this slow reaction to take place and that this restricts the reaction to only go in the forward route, that is $\mathrm{C}_{6} \mathrm{H}_{6} \mathrm{O}_{2}+\mathrm{O}_{2} \rightarrow \mathrm{C}_{6} \mathrm{H}_{4} \mathrm{O}_{2}+\mathrm{H}_{2} \mathrm{O}_{2}$, and does not allow the hydroquinol and $\mathrm{H}_{2} \mathrm{O}_{2}$ to react together again as equation (1). It is also likely that there is a catalyst (maybe a metal or mineral in the earth) that is picked up by the beetle and that this is in the tube enabling this reaction to occur. Rapier [13] in his work of 1928 suggests a somewhat different scheme using catechol and oxygen, which in the presence of the enzyme potato tyrosinase (catechol oxidase) produces $\mathrm{H}_{2} \mathrm{O}_{2}$. Catechol has the same chemical formula as hydroquinol, but the hydroxyls are on adjacent parts of the carbon ring (not opposite as in hydroquinol), so one has

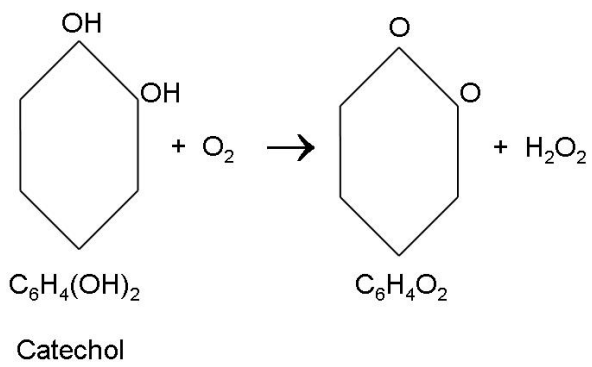

This reaction can be observed in potato tubers and there is a possibility that catechol is being used in the thin tube of the bombardier beetle as well. However, it is difficult to see a chemical pathway emerge back to hydroquinol, so it is more likely that hydroquinol is the starting point as in equation (5) and that there is an abundance of hydroquinol.

If we start in this way, one of the products at the end of the tube would then be Hydrogen Peroxide along with Hydroquinol, which is not used.

\section{Present production of hydrogen peroxide}

The primary use of hydrogen peroxide is the manufacture of "green" bleaching agents, such as perborates and percarbonates, for the paper and textile industries. 
Other significant uses include wastewater treatment and hydrometallurgical processes (for example, the extraction of uranium by oxidation) - see [14].

Most methods of producing $\mathrm{H}_{2} \mathrm{O}_{2}$ today use a combination of hydrogenation and dehydrogenation reactions. This is a batch chemical autoxidation process involving two main stages - a hydrogenation reaction of anthroquinone over $\mathrm{Ni}$ or Pd catalysts producing anthroquinol, then secondly followed by an oxidiser reaction where the anthroquinol is turned back to anthroquinone and hydrogen peroxide. This method involves considerable energy expended in heating and cooling at each stage and condensing out the peroxide from the water $-\mathrm{H}_{2} \mathrm{O}_{2}$ mixture at the end of the process [14]. The anthroquinone can then be reused for the hydrogenating part of the cycle. Laporte Chemicals first set up these methods in 1959 [15] and they are now the most common method of production. Other methods are being considered using more direct routes of direct synthesis of hydrogen and oxygen [16], usually still involving a palladium catalyst.

\section{Discussion and conclusion}

The LaPorte method is costly and needs a considerable outlay in terms of capital expenditure in making the chemical plant, as well as the heating and cooling control systems. Clearly the alternative that is used by the bombardier beetle is of considerable interest since, if the quinol can be made to oxidise at low temperature, then it should be possible to extract hydrogen peroxide by restricting the backwards reaction of the peroxide with the quinone.

In this paper we have shown the unusual route that could well be being used by the bombardier beetle to produce $\mathrm{H}_{2} \mathrm{O}_{2}$. Restricted access to the reverse peroxide reaction (where the $\mathrm{H}_{2} \mathrm{O}_{2}$ breaks back up into $\mathrm{O}_{2}$ and water) is achieved by having the main peroxide production reaction occurring at room temperatures in a very thin tube. It therefore would be valuable to perform experiments where the same quinol oxidation reaction is performed under controlled conditions in a laboratory in order to test the hypothesis advanced here concerning what is happening in this thin tube.

The suggestion is that a restricted access tube of some kind could be the key to resolving the difficulty of mounting the dehydrogenation reaction at room temperature.

\section{Acknowledgements}

A grant from the Institute of Gas Engineers supported Mr. Andreas Prongidis for his $\mathrm{PhD}$ studies at Leeds, which are in a connected area to this research paper of which he is co-author.

The authors are grateful to Dr. John Cooper of the Explosives Group Technical Centre in Stevenston, Ayrshire for his assistance on the chemistry of $\mathrm{H}_{2} \mathrm{O}_{2}$ production in the bombardier beetle. 


\section{References}

[1] Aneshansley, D.J., Eisner, T., Widom, M., Widom, B., "Biochemistry at $100^{\circ} \mathrm{C}$ : Explosive Secretory Discharge of Bombardier Beetles (Brachinus)", Science, 165:61-63, July 1969.

[2] Aneshansley, D.J., Eisner, T., "Spray aiming in the bombardier beetle: Photographic evidence”. Proc. Natl. Acad. Sci. USA, 96:9709-9709, August 1999.

[3] McIntosh, A.C. and Forman, M. "The efficiency of the explosive discharge of the bombardier beetle, with possible biomimetic applications", Design and Nature II, eds. Collins, M.W. and Brebbia, C.A., pp. 227-236, WIT Press, Southampton and Boston, 2004, ISBN: 1-85312-721-3

[4] Beheshti N and McIntosh A C "A biomimetic study of the explosive discharge of the bombardier beetle", Int. J. Des .Nature 1, 61-69. 2007

[5] Beheshti N, McIntosh AC. The bombardier beetle and its use of a pressure relief valve system to deliver a periodic pulsed spray. Bioinspiration and Biomimetics; (Inst of Physics), 2, 57-64, 2007

[6] McIntosh, A.C., "Combustion, fire, and explosion in nature - some biomimetic possibilities”, Proc. IMechE Vol. 221 Part C: J. Mechanical Engineering Science, 1157-1163, 2007

[7] McIntosh, A.C. and Beheshti, N, "Insect inspiration", Physics World, (Inst of Physics), 21(4), 29-31, April 2008.

[8] Beheshti, N. and McIntosh, A.C., "A novel spray system inspired by the bombardier beetle" Design and Nature IV, ed. Brebbia, C.A., pp. 13-22, WIT Press, Southampton and Boston, 2008, ISBN: 978-1-84564-120-7

[9] McIntosh, A. C., "Biomimetic inspiration from fire and combustion in nature including the bombardier beetle" Invited paper in session 7401 'Biomimetics and Bioinspiration', San Diego, August 2009, edited by Raul J. Martin-Palma, Akhlesh Lakhtakia, Proceedings of SPIE Vol. 7401 (SPIE, Bellingham, WA) 74010F, 2009

[10] Schildknecht, H., Holoubek, K.: Angew. Chem. 73, 1-7, 1961.

[11] Aneshansley D J, Eisner T, Widom, M and Widom, B 1969, Biochemistry at $100 \circ \mathrm{C}$ : explosive secretory discharge of bombardier beetles (brachinus) Science 165 61-3.

[12] Private communication with Dr. John Cooper of Explosives Group Technical Centre in Stevenston, Ayrshire.

[13] Rapier, H.S. "The aerobic oxidases", Physiological reviews, 8(2), 245-282, 1928.

[14] Hydrogen Peroxide Production, See web site http://www.cheresources.com/ h2o2.shtml accessed Fri 5/3/10.

[15] Platinum Metals Review 3(2), 54-55, 1959.

[16] Samanta, C., "Direct synthesis of hydrogen peroxide from hydrogen and oxygen: An overview of recent developments in the process", Applied Catalysis A: General 350, 133-149, 2008. 